\title{
Pessoas narrativas: Capão Pecado como literatura pós-colonial
}

\author{
Carolina Correia dos Santos ${ }^{1}$
}

RESUMO: Capão Pecado (2000), escrito por Ferréz, faz parte de um momento recente da literatura brasileira. Por ter sido escrito por um "marginal" e ser sobre a periferia de uma grande cidade do Brasil contemporâneo - tão poucas vezes protagonista na nossa literatura -, o romance apresenta uma proposta politica inerente à obra que é melhor compreendida se analisada, também, via teoria pós-colonial. Este texto visa esboçar esta vertente.

ABSTRACT: Capão Pecado (2000), written by Ferréz, is part of a recent trend in Brazilian literature. Because it was written by a "marginal" writer and being about the suburbs of a big contemporary Brazilian city - rarely a privileged space in this literature -, the novel brings in itself a political purpose better understood via postcolonial theory. This text aims to show this analytical path.

PALAVRAS-CHAVE: Literatura marginal; Teoria pós-colonial; Ferréz KEY WORDS: Marginal literature, Postcolonial theory, Ferréz

I.

Há duas características fundamentais levantadas por Robert Fraser acerca da literatura pós-colonial. A primeira diz respeito à necessidade do sujeito de reconstituir-se, ou seja, depois de uma etapa de subjugação, o sujeito pós-colonial tem, na literatura, a chance de criar sua própria identidade. A segunda é a que afirma que nesta literatura duas perspectivas históricas se confrontam.

No seu livro Lifting the Sentence, Fraser faz um trabalho minucioso de análise de obras ficcionais pós-coloniais, originárias de lugares diferentes, que culmina em didáticos capítulos em torno das qualidades que as obras apresentam. Primeiramente, Fraser identifica

\footnotetext{
${ }^{1}$ Mestre em Teoria Literária e Literatura Comparada pela Universidade de São Paulo. Título do trabalho: "Capão Pecado e a construção do sujeito marginal". Contato: carolinacarolina@usp.br
} 
seis etapas que compõem a literatura pós-colonial. Dessas, três me parecem elucidativas para pensar Capão Pecado. São elas:

1. Narrativas de resistência: caracterizadas essencialmente por pretenderem liberar a imaginação dos nativos do controle imperial e consolidar a vontade da comunidade oprimida.

2. Narrativas de construção da nação: próprias do período pósindependência. Etapa dedicada à exploração da psique da comunidade na qual existe um sentimento de euforia e autoconfiança.

3. Narrativas de dissidência interna: típica da desilusão que se instaura alguns anos após a independência. Volta-se à avaliação e possivel obliteração da herança colonial e de programas compensatórios de resistência e nacionalismo.

Capão Pecado constitui-se coletivamente através da colaboração de outros autores, além de Ferréz, o que pode, portanto, ser entendido como espaço para liberação da criatividade da comunidade oprimida, como caracterizado nas narrativas de resistência. Na falta de outras instâncias, mesmo da possibilidade de expressão via obra própria, os autores conformam o espaço narrativo coletivo. Assim, compõem Capão Pecado, além do próprio romance, "+ 1 AKIM", texto de Ratão; "Se eu quero, eu posso, eu sou”, de Outraversão; "Talvez seja melhor seguir a honestidade", de Negredo; “C.R. Campo de Guerra da nova era”, de Garret; o prefácio (pela edição da Labortexto Editorial) ou posfácio (edição da Objetiva), escrito por Ferréz; e um texto de Mano Brown, “A número 1 sem troféu".

O livro tem como enredo principal a história de vida de Rael, que cresce e vive no bairro do Capão Redondo, periferia de São Paulo. Em linhas gerais, ele é um rapaz diferenciado, dotado de uma perspicácia atípica no meio em que vive, permitindo-lhe entender e, de fato, emitir julgamentos acerca de outros personagens e das situações narradas. Situações que contam, em boa parte, com mortes de amigos e vizinhos, descaso do Estado, abandono, miséria, corrupção e violência. Rael, apesar das adversidades, então, constitui-se um "bom moço": leitor, trabalhador, fiel aos amigos e à mulher. (Na verdade, "por amor", Rael 
cometeria o primeiro de seus "pecados": trair o amigo, então namorado de Paula, por quem se apaixona). Depois de casado e com um filho já, ele é traído pela esposa. Resolve vingar-se e é preso e morto na cadeia.

O romance de Ferréz, por meio deste enredo, mas também de uma forma narrativa bastante "indecisa", se move, basicamente, por meio de forças antagônicas, pendendo ora para um lado, ora para outro.

Uma dessas forças é a construção da "nação", entendida aqui como a comunidade do autor ou personagem, já que ambos provêm do mesmo local. Assim, quando o narrador exagera a confiança em Rael, protagonista do romance, dando-lhe toda atenção e confiando a ele julgamentos de valor, identificamos a euforia em relação ao grau de consciência adquirido pelo sujeito, como o pós-colonial, antes subjugado. Rael representa mais do que seu próprio e único personagem; ele encarna a comunidade, e seus possíveis sucesso e astúcia significam os possíveis sucesso e astúcia da coletividade.

Até este ponto, entrevemos duas das fases que Fraser descreve. Primeiramente, temos um impulso em direção à consolidação da vontade da comunidade oprimida, neste caso, através da possibilidade de Rael vingar, ou se inserir numa outra ordem de vida (podemos pensar na noção de "esfera da ordem" de Antonio Candido, quando este pensa o "malandro"(CANDIDO, 2004, p. 17-46). Além disso, é possível interpretar a própria escritura do livro como a consolidação de uma vontade. Ou de várias, já que há muitos escritores empíricos em Capão Pecado. Depois, a euforia em relação a Rael nos remete à segunda das fases acima. Todo o esforço da narrativa que abre espaço a este personagem pode ser caracterizado como uma tentativa de exploração da psique da comunidade.

Finalmente, o insucesso do personagem corresponderia à etapa das narrativas de dissidência interna, quando a desilusão acontece. Diante da impossibilidade real de êxito social, cultural, econômico e político daquela comunidade (de forma geral, o fracasso diante do 
processo modernizador), Rael se converte em frustração, a prova do insucesso da missão inclusiva moderna.

II.

Fraser afirma que

Since personal and national identities are inevitably intertwined, such grammatical codes (' $I$ ', 'He', 'She', etc.) necessarily entails politics. In a multivalent society where many groups rub shoulders, sharing unequally in power, identification may entail commitment to a particular group or viewpoint. ${ }^{2}$ (2000, p. 65)

Se uma primeira reação aos relatos de caráter antropológico dos colonizadores ao se referirem aos nativos foi uma narrativa em primeira pessoa, com o "eu" fortemente presente - um movimento em direção à visibilidade -, em estágios seguintes, da resistência e construção da nação, a subjetividade narrativa caminha na direção da comunidade que sente a necessidade de autonomia. Esta narrativa, também, tende a ligar o destino individual ao coletivo. É dispensável assinalar a familiaridade destes termos e parâmetros para a narrativa de Capão Pecado, especialmente quando esta se ocupa de Rael. A autonomia de pensamento, a consciência deste personagem, nada mais é do que a consciência que se desejaria despertar na coletividade como um todo.

Capão Pecado, ademais, é escrito em circunstâncias que considero semelhantes às padronizadas por Fraser - resistência e construção da nação. No entanto, ao mesmo tempo, o romance não é uma obra de ficção própria destas circunstâncias se entendida de maneira rigidamente histórico-temporal. É desnecessário reiterar as diferenças entre as ocasiões históricas que Fraser pensa ao elaborar as

\footnotetext{
2 Uma vez que as identidades pessoais e nacionais estão inevitavelmente intricadas, determinados códigos gramaticais ("Eu", "Ele", "Ela", etc.) necessariamente envolvem a politica. Numa sociedade polivalente, onde muitos grupos competem desigualmente pelo poder, identificação pode envolver compromisso com um determinado grupo ou ponto de vista.
} 
etapas narrativas do processo pós-colonial - nações que conquistaram sua independência política nos meados do século XX - e aquela na qual nasce Capão Pecado. Basta ter em mente o período de tempo que separa a descolonização do Brasil e dos ditos países pós-coloniais.

Contudo, se não mais se pode pensar a história como processo linear e comum a todas as nações, impossibilitar a leitura de Capão Pecado via processos característicos de nações pós-coloniais resulta de um erro de leitura do mundo. Além disso, não é a nação brasileira como um todo que está em jogo e é por isso também que Capão Pecado "flerta" com mais de um dos estágios propostos por Fraser.

No caso do romance brasileiro, o "colonizador" a quem se deve resistir é interno, está ao lado, se chama, genericamente, "elite". A "nação" a ser construída não é a brasileira simplesmente - uma vez que a "elite" não faz parte dela -, mas uma fatia desta, que almeja compreensão de si própria, mas que, interessante e problematicamente, se entende "autenticamente brasileira". Talvez porque a identificação encontrada - pobre, favelado, marginal - caracterize uma boa parte dos habitantes do país, muito do ímpeto do autor se concentra em construir uma nação que extrapola a "nação dentro de outra" e que clama para si uma essência brasileira.

Portanto, não é tranquilo o entendimento de Ferréz como autor pós-colonial, uma vez que ele parece insistir na alusão à autenticidade e essência brasileiras. Ou seja, enquanto a literatura pós-colonial vai deliberadamente lutar contra a possibilidade de enxergar qualquer essência (que normalmente leva à homogeneidade) da nação, Ferréz parece empenhar-se em duas direções, que se excluiriam se, de fato, não convivessem: propõe as diferenças ao mesmo tempo em que almeja as semelhanças. Ter em mente as forças contrárias que se encontram na arena do romance, e que se referem à resistência ao colonizador, mas também ao desejo de escrever romance, de construir um herói, de descrever uma realidade, etc., nesse sentido, ajuda a ler a obra de maneira mais acertada. 
Neste sentido, dizer que Capão Pecado é um romance realista é pertinente e o aproxima de toda uma gama de romances que geralmente não são identificados como pós-coloniais na literatura brasileira. Mas certamente esta não poderia ser a única ou principal constatação. Assim, a narrativa em terceira-pessoa, apropriada ao intuito realista, também poder ser, segundo Fraser, notória de um esforço autobiográfico que colocaria o autor como sujeito do processo de construção da nação.

O teórico comenta que a narrativa em terceira-pessoa sempre foi a forma normativa para escritores que tendem ao realismo social, uma vez que, ao menos superficialmente, o escritor se vê livre da armadilha da subjetividade. A aparente objetividade corroboraria com o intuito da obra de "abrir os olhos" do leitor às injustiças e atrocidades típicas de um período de grandes injustiças sociais. Essa objetividade, também, idealmente geraria todo um impeto especulativo em relação ao protagonista cuja psique, desejos intimos e pensamentos são pouco revelados. No entanto, assinala Fraser (2000, p. 87),

the third person singular was to be used as vehicle for a variety of autobiographical fiction in which the acknowledged drives of the self, either the author's own or that of somebody like him or her, were distanced as a social object. This was increasingly the case during periods of resistance and nation-building when sociological generalization became a means of 'fixing' the self as part of a distinct and integrated community. ${ }^{3}$

Esta observação nos leva a ponderar sobre o papel do escritor de Capão Pecado de maneira mais pontual. É claro que ao assumir que o romance brasileiro pode ser lido nos termos da literatura pós-colonial, concordo que há uma relação íntima entre as circunstâncias sócioeconômico-históricas do seu autor e comunidade e o livro. Assim, o erro

\footnotetext{
${ }^{3}$ A terceira pessoa do singular era para ser usada como veículo para uma variedade de ficção autobiográfica na qual os conhecidos movimentos do "eu", do próprio autor ou de alguém como ele ou ela, ficavam distanciados, como objetos sociais. Estes foram os casos nos períodos de resistência ou de construção da nação quando a generalização sociológica se torna uma maneira de "fixar" o "eu" como parte de uma comunidade distinta e integrada.
} 
de uma leitura simplista do uso da terceira pessoa do singular em Capão Pecado, derivado do desconhecimento de um intuito um pouco mais complexo a meu ver, levaria a constatações que entendem este esforço narrativo como aquele meramente usado para criar distância entre narrador e personagens. Ou seja, entendo que neste romance Rael encarna um pouco do autor, bem como da sua comunidade, que é a comunidade do livro. Os três elementos - autor, personagem e comunidade - têm afinidade porque, arrisco, provém da mesma matéria. Rael personifica as três entidades.

No sentido de tentar entender a relação do personagem com a comunidade, uma analogia interessante pode ser traçada em relação à análise de Fraser sobre o protagonista de Things Fall Apart, romance de Chinua Achebe, escrito em 1958.

O crítico comenta que o livro funciona como uma tragédia na qual a pergunta que surge é até que extensão Okonkwo - o protagonista deve ser visto como um típico membro da sua sociedade, e sua desgraça e suicídio sintomas de um colapso geral. Fraser afirma que encontrar na obra somente uma parábola de opressão colonial, como tantos fizeram ${ }^{4}$, limita o livro, ainda que uma apologia a um jeito de vida, a uma tradição, também esteja no horizonte interpretativo.

A opressão colonial é eficientemente mostrada na ignorância com que os ingleses abordam a sociedade à qual Okonkwo pertence, demandando um tipo de comportamento social que não condiz com os valores daquela sociedade. As consequências deste engano são percebidas através do protagonista que tem seu direito à

\footnotetext{
4 Esta observação de Fraser parece se pautar, ao menos parcialmente, no ensaio de Fredric Jameson, "Third World Literature in the Era of Multinational Capitalism" (1986). Nele, Jameson faz a categórica e famosa afirmação de que toda a literatura produzida no terceiro-mundo é, necessariamente, uma alegoria nacional. O percurso do seu argumento é profundamente discutido por Aijaz Ahmad (1987), num ensaio que também se tornou célebre e que refutará, entre outros aspectos levantados por Jameson, o fato de que todas as obras literárias do terceiro-mundo têm em seu horizonte a nação ou o nacionalismo exclusivamente. De fato, como inclusive assinala Ahmad, o ponto forte do ensaio de Jameson (seu melhor argumento até) é o abandono do "nacional" em favor do "coletivo". Assim, o americano, no final do seu texto, afirmaria que a história e a experiência individuais na mencionada literatura só podem, na verdade, aludir à experiência da coletividade.
} 
individualidade suprimido reagindo de maneira exacerbada, cometendo abusos, principalmente os que se referem aos limites da ordem social. A situação se agrava quando ele, depois da punição que recebe, volta à sua aldeia para encontrá-la tomada pelos britânicos. Desorientado, Okonkwo sugere resistência, mas está fora de sintonia com a sociedade que não reage como ele, causando seu desespero e suicídio. Fraser (2000, p. 89) explica que Okonkwo viveu sua vida na esperança de uma ação heróica e quando sua comunidade se nega a honrar seus valores, ele sucumbe à confusão e comete suicídio.

A pergunta colocada por Fraser em relação a Okonkwo também é, em alguma medida, motor da minha interpretação de Capão Pecado: até que ponto Rael pode ser visto como um típico membro da sua sociedade? E, assim como em Things Fall Apart, o romance brasileiro também poderia ser lido como uma parábola? Evidentemente, a alegoria aqui diria respeito à opressão social a que estão submetidos os habitantes pobres dos grandes centros urbanos brasileiros, mas, talvez, não só.

Diferentemente da narrativa nigeriana, o narrador em terceira pessoa de Capão Pecado acompanha o protagonista de muito perto, não permitindo distância alguma, e, em determinada medida, guiando seu leitor à ilusão da autoconfiança do protagonista e à crença nos seus julgamentos. A distância e o equilíbrio, segundo Fraser, que a narrativa de Achebe desempenha não permitem que o leitor entenda a história através de Okonkwo, técnica da qual a narrativa de Capão Pecado não lança mão.

Ainda que com estratégias diferentes, o resultado é parecido. Assim como Okonkwo, Rael deixa de ser um homem do seu meio quando deseja exercer sua individualidade ao extremo. Ele perde a sintonia com sua comunidade quando despreza as regras da vida na qual está inserido (ele trai o amigo). Viver a história de amor com Paula deflagra o desrespeito às leis sociais da sua coletividade. Isolar-se dos amigos é sua única opção, sugerindo que o protagonista não mais 
comunga dos valores daquela sociedade e é incapaz de nela viver como antes.

Por outro lado, quando colocado realmente à prova, Rael recua e nisso difere do personagem de Achebe. O desespero ao se confrontar com circunstâncias totalmente adversas e inesperadas - consequências da sua individualidade - não permite ponderação: não sabemos se Rael reflete sobre o crime que vai cometer; ao contrário, temos a impressão de que a decisão de matar seu Oscar foi tomada rapidamente, uma resposta emocional àquela situação. Portanto aqui o narrador não dá ao personagem o direito de expor seus pensamentos; as ações passam a pesar mais. A reação de Rael, ao contrário da de Okonkwo - que, inclusive, toma uma atitude bem individual e "moderna" -, é uma tentativa de retorno aos valores antes abandonados: Rael vai se vingar, vai fazê-lo "pela honra".

Este texto não visa, pois não conseguiria num curto espaço, desenvolver hipóteses do que esta "volta" aos valores da comunidade poderiam significar. Basta, por hora, "provocar" o leitor com a sugestão de que esses valores, possivelmente taxados de irracionais, levam-nos à leitura de uma contestação dos valores da modernidade, tema que, é bom lembrar, não é estranho à literatura pós-colonial. Se assim for, Rael reiteraria o fracasso do projeto brasileiro de modernidade que contou com o apoio de boa parte de literatura do século passado para surgir. Um possivel aviso vindo da periferia.

\section{Referências Bibliográficas:}

AHMAD, Aijaz. "Jameson's Rhetoric of Otherness in 'National Allegory". In: Social Text, N. 17 (Autumn, 1987), p. 3-25.

CANDIDO, Antonio. "A dialética da malandragem". In: O Discurso e a Cidade. São Paulo; Rio de Janeiro: Duas Cidades; Ouro sobre Azul, 2004, p. 17-46.

FERRÉZ. Capão Pecado. São Paulo: Objetiva, 2005. 
FRASER, Robert. Lifting the sentence: a poetics of postcolonial fiction. Manchester and New York: Manchester University Press, 2000.

JAMESON, Fredric. "Third-World Literature in the Era of the Multinational Capitalism". Social Text, N. 15 (Autumn, 1986). p. 65-88. 